\title{
Author Correction: Psychopathy
}

Stephane A. De Brito (i), Adelle E. Forth, Arielle R. Baskin-Sommers, Inti A. Brazil, Eva R. Kimonis, Dustin Pardini, Paul J. Frick, Robert James R. Blair and Essi Viding

Correction to: Nature Reviews Disease Primers https://doi.org/10.1038/s41572-021-00282-1, published online 08 July 2021.

In the original version of this Primer, several names were incorrectly omitted from the Author contributions statement; E.R.K. was omitted from Epidemiology, A.R.B.-S. was omitted from Mechanisms/pathophysiology and I.A.B. and A.R.B.-S were omitted from Outlook. Also, the link for the Society for the Scientific Study of Psychopathy was omitted from the Related links box. These errors have been corrected in the HTML and PDF versions of the manuscript.

https://doi.org/10.1038/s41572-021-00312-y | Published online: 01 October 2021

(C) Springer Nature Limited 2021 